\section{Biologische Datenbanken}

\section{J. Arnemann}

Abteilung Molekulargenetik, Labor Dr. Wisplinghoff, Köln, Deutschland

Synonym(e) Molekularbiologische Datenbanken

Englischer Begriff biological databases

Definition Biologische Datenbanken sind online zugängliche Speicher zu biologischen Informationen der unterschiedlichsten Kategorien. Eine jährliche Übersicht wird im Journal Nucleic Acids Research publiziert und enthielt 2016 insgesamt 180 derartige Datenbanken.

Beschreibung Die Datenbanken lassen sich inhaltlich in unterschiedliche Kategorien einteilen:

1. Übergeordnet stehen die sog. Meta-Databases, die wiederum die Daten aus anderen Datenbanken zusammenfassen und sie in anderer Form verfügbar machen, wobei der Schwerpunkt auf Krankheiten und Organismen liegt. Beispiele hierfür sind die Datenbanken GeneCards oder Human Epigenome Atlas.
2. Weiterhin existieren Datenbanken zu spezifischen Bereichen, wie z. B. Nukleinsäure-Datenbanken, die DNA-Sequenzdatenbanken, Genom-Datenbanken, ExpressionsDatenbanken, RNA-Datenbanken, aber auch sekundäre Datenbanken, wie OMIM (Online Mendelian Inheritance In Man) oder andere Phänotyp-Datenbanken auflisten.

3. Es existieren ebenso Aminosäure- bzw. Protein-Datenbanken, die wiederum Datenbanken zu Protein-Sequenzen, -Strukturen, -Modellen, Protein-Protein-Interaktionen oder Proteomics-Datenbanken enthalten.

4. Einen weiteren Bereich machen die sog. zusätzlichen Datenbanken aus, die meist anwendungsbezogene, interdisziplinäre Datenbanken enthalten, wie z. B. SignalTransduction-Pathway, Metabolic Pathways, TaxonomicDatabase, Mathematical-Model-Database oder andere, oftmals sehr spezialisierte Datenbanken, wie beispielsweise Antibody-Registry oder p53-Database.

\section{Literatur}

http://www.oxfordjournals.org/nar/database/c/. Zugegrieffen am 05.06.2018 Rigden DJ et al (2016) The 2016 database issue of Nucleic Acids Research and an updated molecular biology database collection. Nucleic Acids Res 44(D1):D1-D6 